ISSN: 2528-9527

E-ISSN : 2528-9535

YIl Year: 11

Cilt Volume: 17

Sayı Issue: 35

Mart March 2021

Makalenin Geliș Tarihi Received Date. 22/08/2020

Makalenin Kabul Tarihi Accepted Date. 25/03/2021

\title{
Helikopter Anne Tutumları: Üniversite Öğrencilerinin Yaşam Doyumları ve Psikolojik İyi Oluşları Üzerindeki Yordayıı Rolü
}

DOI: 10.26466/opus.784171

$*$

\author{
Faruk Caner Yam* - Hatice Kumcağız ** \\ *Öğretim Görevlisi, Tokat Gaziospamapaşa Üniversitesi, Tokat, Türkiye \\ E-Posta: farukcaneryam@hotmail.com \\ ORCID: 0000-0001-8392-9576 \\ ** Doç. Dr., Ondokuz Mayıs Üniversitesi, Samsun, Türkiye \\ E-Posta: haticek@omu.edu.tr \\ ORCID: 0000-0002-0165-3535
}

\begin{abstract}
$\ddot{O} z$
Bu araştırmada üniversite öğrencilerinin annelerinden alglladıklar helikopter ebeveyn tutumlarının yaşam doyumları ve psikolojik iyi oluşları üzerindeki yordayıcı rolünü incelemek amaçlanmıştır. Araştırmanın çalışma grubu 166's kadın ve 74'ü erkek olmak üzere 240 üniversite öğrencisinden oluşmaktadır. Araştırmada veri toplama aracı olarak Helikopter Ebeveyn Ölçeği, Yaşam Doyumu Ölçeği ve Psikolojik İyi Oluş Ölçeği kullanılmıştır. Elde edilen verilerin standart sapma, ortalama, basıklık ve çarpıklık değerleri hesaplanmıştır. Ayrıca psikolojik iyi oluş, yaşam doyumu ve algilanan helikopter anne tutumu değişkeleri arasındaki ilişkiyi değerlendirmek için Pearson Momentler Çarpımı Korelasyon analizi kullanılmıştır. Diğer açıdan algılanan helikopter anne tutumunun üniversite öğrencilerinin yaşam doyumları ve psikolojik iyi oluş düzeyleri üzerindeki yordayıcı rolünü incelemek için basit doğrusal regresyon analizi kullanılmıştır. Yapılan regresyon analizinin sonucuna göre üniversite öğrencilerinin annelerinden algıladıkları helikopter ebeveyn tutumlarını yaşam doyumları ve psikolojik iyi oluşlarn üzerinde negatif yordayıcı etkisinin olduğu görülmüştür. Diğer bir ifadeyle bu sonuç üniversite öğrencilerinin annelerinden algıladıkları helikopter ebeveyn tutumları yükseldikçe yaşam doyumları ile psikolojik iyi oluş düzeylerinde azalmanın meydana geleceğine işaret etmektedir. Araştırmada elde edilen bulgular alanyazındaki diğer araştırma sonuçlarn ile tartışılmış ve araştırmacılara öneriler sunulmuştur.
\end{abstract}

Anahtar Kelimeler: helikopter ebeveynlik, psikolojik iyi oluş, yaşam doyumu 
ISSN: 2528-9527

E-ISSN : 2528-9535

Yıl Year: 11

Cilt Volume: 17

Sayı Issue: 35

Mart March 2021

Makalenin Gelis Tarihi Received Date. 22/08/2020

Makalenin Kabul Tarihi Accepted Date. 25/03/2021

\title{
Helicopter Mother Attitudes: The Predictive Role in University Students' Life Satisfaction and Psychological Well-Being
}

\begin{abstract}
In this study, it was aimed to examine the predictive role of helicopter parental attitudes perceived by university students from their mothers on their life satisfaction and psychological well-being. The study group of the consists of 240 university students, 166 of whom are women and 74 men. Helicopter Parent Attitude Scale, Life Satisfaction Scale and Psychological Well-being Scale were used as data collection tools in the study. Descriptive statistics of the collected data were calculated. In addition, Pearson Product Moment Correlation analysis was used to evaluate the relationship between psychological well-being, life satisfaction and perceived helicopter mother attitude variables. On the other hand, simple linear regression analysis was used to examine the predictive role of perceived helicopter mother attitude on university students' life satisfaction and psychological well-being. According to the results of the regression analysis, it was seen that the helicopter parental attitudes that university students perceived from their mothers had a negative predictive effect on their life satisfaction and psychological well-being. In other words, this result indicates that as the helicopter parental attitudes perceived by university students from their mothers increase, their life satisfaction and psychological well-being levels will decrease. The findings obtained in the study were discussed with other research results in the literature, and various suggestions were presented for further research.
\end{abstract}

Keywords: helicopter parenting, psychological well-being, life satisfaction. 


\section{Giriş}

Helikopter ebeveynlik kavramı, çocuklarının üzerine aşırı bir şekilde düşen, çocukların tüm gelişim alanlarıyla ihtiyaç duyulandan fazla ilgilenen, çocukları adına karar veren, zorlukları ve problemleri çocukları adına çözmeye çalışan aşırı koruyucu anne baba tutumları olarak ifade edilmektedir (Cline ve Fay, 1990; Nelson, 2010). Bu tutumuna sahip aileler çocuklarının okul hayatı, arkadaşlık ilişkileri, yemek yeme alışkanlıkları gibi alanlar üzerinde de rahatsızlık verecek düzeyde ilgili olmaya çalışmaktadırlar (Bradley-Geist ve Olson-Buchanan, 2014). Bu nedenle helicopter ebeveynler çocuklarının tüm alanlardaki eksikliklerini gidermek için aşırı şekilde çabalamakta ve çocuklarının her alanda başarı elde etmeleri konusunda çok fazla beklenti içerisine girmektedirler (LeMoyne ve Buchanan, 2011). Helikopter ebeveynler, çocukları üzerinde sürekli olarak bir kalkan görevi görme, çocukların karşılaştıkları sorunlara onlardan önce çözüm bulma gibi davranışlar sergilemektedirler (Yılmaz ve Büyükcebeci, 2019). Diğer açıdan helikopter ebeveyn tutuma sahip aileler çocukları adına fazlaca endişe duydukları için okul yaşantısı, günlük hayatta kendini olumsuzluklara karşı koruma ve çeşitli alanlardaki tercihler konusunda sürekli olarak tavsiye ve ögütler vermekten kendilerini alıkoyamamaktadırlar (Reed, Duncan, Lucier-Greer ve Fixelle, 2016). Öyle ki helikopter ebeveynler, çocukları ile ilgilenme konusunu takıntılı bir düzeye çıkarmakta ve bu davranışları sürdrümeyi normal olarak görmektedirler (Schiffrin ve vd., 2013).

Helikopter anne-babalar sergilemiş oldukları davranışlarla çocuklarının iyiliğini düşünüyor gibi görünseler de bu davranışların çocuklar üzerinde birçok olumsuz etkisi bulunmaktadır. Alanyazında bu tutuma sahip olan ailelerin çocuklarında problem çözme becerilerinde zayıflıklar (Gibbs, 2009), özgüven eksiliği (Padilla-Walker ve Nelson, 2012; Rutherford, 2011) ve psikoloji açıdan dayanıksız olma gibi sorunların oluştuğu rapor edilmiştir. Bunun yanı sıra helikopter ebeveyn tutumlarının çocukların okul başarılarında düşüşlere (Shoup, Gonyea, ve Kuh, 2009), mükemmeliyetçi ve narsistik kişilik gelişimine (Segrin, Woszidlo, Givertz, Dauer, ve Murphy, 2012) neden olduğu ifade edilmektedir. Diğer açıdan yapılan bazı araştırmalarda helikopter ebeveynlerin yetiştirmiş oldukları çocukların ileriki yaşamlarında iş seçimi konusunda sorunlar yaşadıkları (Tyler, 2007), kişilerarası bağımlılık düzeylerinin yüksek olduğu (Odenweller, Booth-Butterfield ve Weber, 
2014), yaşam tatminlerinin düşük olduğu (Schiffrin ve vd., 2013) sonuçlarına ulaşılmıştır. Benzer şekilde helikopter tutuma sahip ebeveynleri olan çocukların yetişkinlik döneminde karar verme becerilerinde sorun yaşadıkları ve psikososyal açıdan gerekli olgunluğa ulaşamadıkları ifade edilmektedir (LeMoyne ve Buchanan, 2011; Reed, Duncan, Lucier-Greer ve Fixelle, 2016). Yukarıdaki açıklamalar ve araştırma sonuçları göz önüne alındığı bireylerin helikopter ebeveyn davranışlarına daha çok çocukluk döneminde maruz kalmalarına rağmen bu tutumların olumsuz etkilerinin yetişkinlik dönemlerine kadar uzadığı dikkati çekmektedir.

İyi oluş, pozitif psikolojinin en önemli kavramlarından birisidir (Diener, Scollon ve Lucas, 2009; Keyes, Shmotkin ve Ryff, 2002; Seligman, 2011). Bu kavram incelendiğinde alanyazında öznel iyi oluş ve psikolojik iyi oluş gibi farklı konseptlerinin bulunduğu görülmektedir. Deiner (1984) tarafından ortaya atılan ve günlük hayattaki mutluluk ile ilişkili olan öznel iyi oluş kavramı, bireyin olumlu duyguları daha sık, olumsuz duyguları daha az yaşaması ve içinde bulunduğu yaşamdan memnun olma düzeyi olarak tanımlamıştır. Diğer bir ifadeyle öznel iyi oluş bireyin kendi yaşamına yönelik bilişsel ve duyuşsal yargılarının tamamıdır (Diener, 2000; Lyubomirsky, Sousa ve Dickerhoof, 2006).

Pozitif psikoloji alanındaki bazı araştırmacılar, Diener' in (1984) geliştirmiş olduğu öznel iyi oluş kavramın büyük oranda bireyin mutlu olup olmamasıyla ilgilendiğini öne sürerek hazcı bir yaklaşım olduğu konusunda eleştirmişlerdir. Bu gelişmelerin ardından Ryff (1989) iyi oluş kavramının sadece mutlu olup olmama ile açıklanamayacağını ifade etmiş ve psikolojik işlevsellik kriterini temeline alarak psikolojik iyi oluş kavramını geliştirmiştir. Psikolojik iyi oluş, bireyin hayatta karşılamış olduğu her türlü yaşamsal olaylara karşı ortaya koymuş olduğu varoluşsal meydan okumaları şeklide tanımlanmaktadır (Ryff, 1989). Diğer açıdan psikolojik iyi oluş kavramı kendini kabul, olumlu sosyal ilişkiler, özerk olma, çevresini kontrol edebilme, yaşamın anlamı ve kendini geliştirmesi motivasyonu şeklinde altı boyuttan oluşan kapsamışı bir kavramdır (Keyes, Shmotkin ve Ryff, 2002). Ryff (2014) tanımlamış olduğu bu altı boyutu bireyin ruhsal sağlığının yerinde oluşuna katkı sağlayan faktörler olduğunu belirtmiştir. Bundan dolayı kendisi ve çevresiyle iyi ilişkiler geliştiren, kendini kabul düzeyi yüksek olan, hayatta bir amaca tutunmuş ve yaşadığı hayata bir anlam yüklemiş 
olan bireylerin psikolojik iyi oluşlarının yüksek olacağı ve dolasıyla ruhsal açıdan sağlıklı bireyler olacakları ifade edilmektedir (Ryff, 2018).

Yaşam doyumu, bireyin yaşamının tüm yönlerine ilişkin bilişsel değerlendirmeleri olarak tanımlanmaktadır (Diener, Emmons, Larsen ve Griffin, 1985). Diğer bir ifadeyle yaşam doyumu, bireyin hayatına dair beklentileriyle içinde bulunduğu yaşamının koşullarını kıyaslaması sonucunda elde ettiği memnuniyet seviyesidir (Diener ve Lucas, 1999; Myers ve Diener, 1995). Bireylerin yaşam doyumları üzerinde aile, ekonomik koşullar, sosyal çevre, akademik ve iş yaşantıları gibi birçok faktör etkili olabilmektedir. (Diener ve Diener, 1995; Appleton ve Song, 2008; Suldo, Riley ve Shaffer, 2006). Yukarıda sayılan faktörlere ilişkin memnuniyet düzeyleri bireylerin yaşam doyumları üzerinde etkili olmaktadır (Diener, 2000). Diğer açıdan yaşam doyumu kavramı, öznel iyi oluş kavramlarının bilişsel boyunu oluşturduğu için bireylerin yaşam doyumları öznel iyi oluşlarını da doğrudan etkileyen bir kavramdır (Diener, 1984).

Alanyazında yapılmış araştırmalarda helikopter ebeveyn tutumlarının çocuklarda akademik başarı kaygısına, özgüven eksikliğine, psikolojik dayanıksızlığa, mükemmeliyetçi tutumların gelişmesine ve depresyon yaşamalarına neden olduğu tespit edilmiştir (Gibbs, 2009; Odenweller ve vd., 2014; Segrin, ve vd., 2012; Tyler, 2007). Diğer açıdan sınırlı sayıda yapılan bazı araştırmalarda helikopter ebeveyn tutumlarının sadece çocukluk dönemindeki bireyleri üzerinde olumsuz etkisinin olmadığı benzer şekilde yetişkin bireylerin de yaşamları üzerinde olumsuz etkilerinin olduğu bildirilmiştir (Reed ve vd., 2016; Odenweller, Booth-Butterfield ve Weber, 2014). Helikopter ebeveyn tutumlarının bireylerin tüm gelişim alanları ve dönemleri üzerinde olumsuz etkisinin olabildiği ifade edilmesine rağmen alanyazında incelendiğinde yetişkinlik dönemdeki bireyleri konu alan araştırmaların oldukça az olduğu ifade edilmektedir (Yılmaz ve Büyükcebeci, 2019). Tüm bu gerekçelerden dolayı bu araştırmada üniversite öğrencilerinin annelerinden algıladıkları helikopter ebeveyn tutumları ile psikolojik iyi oluş ve yaşam doyumları arasındaki ilişkiyi incelemek amaçlanmıştır. Bu amaç doğrultusunda aşağıdaki sorulara yanıt aranmaya çalışılmıştır:

1- Üniversite öğrencilerinin annelerinden algıladıkları helikopter ebeveyn tutumlarının yaşam doyumları üzerinde anlamlı bir yordayıcı etkisi bulunmakta midır? 
2- Üniversite öğrencilerinin annelerinde algıladıkları helikopter ebeveyn tutumlarının psikolojik iyi oluşları üzerinde anlamlı bir yordayıcı etkisi bulunmakta mıdır?

\section{Yöntem}

\section{Araştırmanın Modeli}

$\mathrm{Bu}$ çalışma üniversite öğrencilerinin annelerinden algıladıkları helikopter ebeveyn tutumlarının yaşam doyumları ile psikolojik iyi oluş düzeyleri üzerindeki yordayıcı etkisinin olup olmadığının inceledndiği ilişkisel tarama modelinde tasarlanmış bir araştırmadır. İlişkisel tarama modeli değişkenler arasındaki ilişkiyi incelemek için kullanılan bir modelidir (Böke, 2014). Ayrıca ilişkisel tarama modellerinde değişkenler arasındaki ilişkinlerin belirlenmesinin yanı sıra aynı zamanda bir değişkenin diğer bir değişkene ait varyansı açıklama gücünün olup olmadığının da incelenebildiği araştırma modelidir (Büyüköztürk, Çakmak, Akgün, Karadeniz ve Demirel, 2017; Karasar, 2011).

\section{Araştırma Grubu}

Araştırmanın çalışma grubu amaçlı örneklem yöntemlerinden olan kolay örnekleme yöntemi ile belirlenmiştir. Kolay örnekleme yönteminde araştırmacı ulaşım, maliyet ve zaman açısından tasarruf sağlamak için araştırmasının amacına uygun veriler toplayacağını düşündüğü bir grubu örneklem grubu olarak belirlemeyebilmektedir (Büyüköztürk vd., 2017; Karasar, 2011). Araştırmanın örneklem grubunu Orta Karadeniz Bölgesinde bulunan bir üniversitedeki 166'sı kadın (\%69.2) ve 74'ü (\%30.8) erkek olmak üzere 240 üniversite öğrencisi oluşturmaktadır. Örneklem grubundaki öğrencilerin yaşları 18 ile 26 arasında değişmektedir $(X=20.87$; Ss $=1.76)$. Sınıf seviyeleri ise 1 ile 4 arasında değişmekte olup, öğrencilerden 41'i birinci sinıfa (\%17.1), 67'si ikinci sinıfa (\%27.9), 59'u üçüncü sınıfa (\%24.6) ve 73'ü dördüncü sınıfa (\%30.4) devam etmektedir. Ayrıca öğrencilerin annelerinin 191'i bir iş kolunda çalışmaktayken (\%79.6), 49'u ise herhangi bir işte çalışmamaktadır (\%20.4). Diğer açıdan örneklem grubundaki üniversite öğrencilerinin anne eğitim düzeylerine bakıldığı zaman 20'sinin oku-yazar olmad1ğ1 (\%8.3), 118'nini ilkokul (49.2), 43'ünün ortaokul (\%17.9), 37'sini lise (\%15.4) ve 22'sinin lisans (\%9.2) mezunu oldukları görülmüştür. 


\section{Veri Toplama Araçları}

Helikopter Ebeveyn Tutum Ölçeği: Helikopter Ebeveyn Tutum Ölçeği Yılmaz (2019) tarafından bireylerin anne ve babalarından algıladıkları helikopter ebeveyn tutumlarını değerlendirmek üzere geliştirilmiştir. Ölçek anne ve baba formlarından oluşmaktadır. Her iki ölçek formu yirmi madde ve dört alt boyuttan oluşmaktadır. Yılmaz (2019) tarafından yapılan ölçek geliştirme çalışmasında anneden ve babadan algılanan helikopter ebeveyn tutumları ayrı olarak analiz edilmiştir. Ölçek toplam puanı üzerinden yorumlanabilmekte, ayrıca bireylerin anne ve babalarından algıladıkları helikopter ebeveyn tutumları etik ve ahlaki konularda helikopterlik, okul yaşamına dair helikopterlik, temel güven ve yaşam becerileri konusunda helikopterlik ve duygusal-kişisel yaşam alanında helikopterlik tutumları açısından da değerlendirilmektedir. Anneden algılanan ebeveyn tutumlarına ilişkin yapılan faktör analizi sonucunda faktör yükleri .54 ile .82 arasında değişen, toplam varsayın \%46'sının açıklama gücü olan dört faktörlü bir yapı elde etmişledir. Ölçeğin iç tutarlık katsayısını (Cronbach Alfa) .85 olarak hesaplamıştır. Mevcut çalışmada ölçeğin anneden algılanan helikopter tutumunu değerlendiren formu kullanılmış ve analizler ölçeğin toplam puanı üzerinden yapılmıştır. Ayrıca Helikopter Anne Tutumu Ölçeği'nin bu çalışmada toplanan veriler üzerinden hesaplanan iç tutarlık katsayısı (Cronbach Alfa) .83 olarak bulunmuştur.

Psikolojik İyi Oluş Ölçeği: Diener ve arkadaşlarının (2009) geliştirmiş olduğu Psikolojik İyi Oluş Ölçeği, Telef (2013) tarafından Türkçeye uyarlanmıştır. Ölçek tek boyut ve sekiz maddeden oluşmaktadır. Telef (2013) gerçekleştirmiş olduğu uyarlamasında ölçeğin yapısını doğrulayıcı faktör analiziyle incelemiş ve çalışma sonucunda elde etmiş olduğu model uyum indekslerine göre $(\mathrm{x} 2 / \mathrm{sd}=4.64, \mathrm{RMSEA}=.08, \mathrm{SRMR}=.04, \mathrm{CFI}=0.95$; RFI= $.92 \mathrm{GFI}=.96, \mathrm{NFI}=.94$, ve $\mathrm{IFI}=.95)$ ölçeğin yapısının doğrulandığı sonucuna ulaşmıştır. Diğer açıdan uyarlama çalışması sırasında ölçeğin Cronbach Alfa iç tutarlık katsayısı .80 olarak hesaplanmıştır (Telef, 2013). Psikolojik İyi Oluş Ölçeği'nin mevcut çalışmada toplanan veriler üzerinden hesaplanan Cronbach Alfa iç tutarlık katsayısı .87 olarak bulunmuştur.

Yaşam Doyumu Ölçeği: Bireylerin genel yaşam doyumunu değerlendirmek için Diener, Emmons, Larsen ve Griffin (1985) tarafından geliştirmiş olan 
Yaşam Doyum Ölçeği, Köker (1991) tarafından Türkçeye uyarlanmıştır. Ölçme aracı tek boyut, beş maddeden oluşmakta ve yedili likert tipinde derecelendirilmiştir. Köker (1991) yapmış olduğu uyarlama çalışmasında ölçeğin faktör yüklerinin .71 ile .80 arasında değiştiğini raporlamıştır. Diğer açından yapılan uyarlama çalışmasında test tekrar test güvenilirlik yöntemi kullanılmış ve sonuç .85 olarak hesaplamıştır. Yaşam Doyumu Ölçeği'nin mevcut çalışmada elde edilen veriler üzerinden hesaplanan Cronbach Alfa iç tutarlık katsayısı ise .84 olarak bulunmuştur.

\section{Verilerin Toplanmast}

Araştırma gerçekleştirilmeden önce Ondokuz Mayıs Üniversitesi Sosyal ve Beşeri Bilimleri Bilimler Etik Kurulu'ndan (17/04/2020 tarih ve Karar no: 2019179) izin alınmıştır. Araştırmada kullanılan ölçme araçları internet tabanlı hale dönüştürülmüştür. Daha sonra çalışma yapılacak olan öğrenci grubuna, ölçme araçlarına ait araştırma linki gönderilmiştir. Ölçme araçları internet tabanlı hale getirilirken, en üst bölüme "araştırma gönüllü katıllm formu" eklenmiş ve çalışmanın verileri gönüllük ilkesine göre toplanmıştır. Ardından belirli bir süreyle katılımcıların gönderilen ölçme araçlarının cevaplanması beklenmiş ve ölçme araçlarını cevaplayan 240 katılımcı ile çalışma sürdürülmüştür.

\section{Verilerin Analizi}

Araştırmada öncelikli olarak toplanan verilere ait betimleyici istatistiklerini incelemiş, bu doğrultuda verilerin standart sapma, ortalama, basıklık ve çarpıklık değerleri hesaplanmıştır. Ayrıca psikolojik iyi oluş, yaşam doyumu ve algılanan helikopter anne tutumu değişkeleri arasındaki ilişkiyi değerlendirmek için Pearson Momentler Çarpımı Korelasyon (r) analizi kullanılmıştır. Diğer açıdan algılanan helikopter anne tutumunun üniversite öğrencilerinin yaşam doyumları ve psikolojik iyi oluş düzeyleri üzerindeki yordayıcı rolünü incelemek için ise basit doğrusal regresyon analizi kullanılmıştır. Regresyon analizinin doğrusallık ve hata terimlerinin normal dağılıma sahip olması koşullarını incelemek için ise histogram ve p-p plot grafikleri kullanılmıştır. 


\section{Bulgular}

\section{Araştırmada Elde Edilen Verilerin Betimsel İstatistiklerine İlişkin Bulgular}

Araştırmaya katılan üniversite öğrencilerinden elde edilen yaşam doyumu, psikolojik iyi oluş ve algılana helikopter anne tutumu ölçeklerine ait puanlar betimleyici istatistikleri Tablo 1'de sunulmuştur.

Tablo 1. Çalışmada toplanan verilere ait betimleyici istatistikler

\begin{tabular}{llllll}
\hline Değişkenler & $\mathbf{n}$ & $\mathbf{X}$ & Ss & Çarpıklık & Basıklık \\
\hline Yaşam Doyumu & 240 & 16.23 & 3.84 & .063 & -.181 \\
Psikolojik İyi Oluş & 240 & 40.03 & 8.02 & -.299 & -.340 \\
Helikopter Anne Tutumu & 240 & 46.45 & 11.54 & .418 & -.313 \\
\hline
\end{tabular}

Tablo 1'de görüldüğü üzere araştırmada toplanan verilerin normal dağ1lım gösterip göstermediğini değerlendirmek için basıklık ve çarpıklık katsayıları incelenmiştir. Bu değerlerin normal dağılıma işaret etmesi için +1.5 ile1.5 arasında olması gerektiği söylenmektedir. (Tabachnick ve Fidell, 2013). Tablo 1 incelendiğinde tüm değişkenlere ait basıklık ve çarpıklık değerlerinin alanyazındaki önerilen aralıkta olduğu görülmektedir. Sonuç olarak araştırmada toplanan verilerin normal dağılıma sahip olduğu değerlendirilmiştir.

Diğer açıdan regresyon analizine başlamadan önce değişkenler arasındaki incelemek için korelasyon analizi yapılmış ve Tablo 2'de sunulmuştur.

Tablo 2. Regresyon analizine kullanilacak olan değişkenler arasindaki korelasyon bulgularn

\begin{tabular}{llllll}
\hline Değişkenler & $\overline{\mathrm{x}}$ & $\mathrm{S}$ & 1 & 2 & 3 \\
\hline 1.Yaşam Doyumu & 16.23 & 3.84 & 1 & & \\
2.Psikolojik İyi Oluş & 40.03 & 8.02 & $.75^{* *}$ & 1 & \\
3.Helikopter Anne Tutumu & 46.45 & 11.54 & $-.43^{* *}$ & $-44^{* *}$ & 1 \\
\hline
\end{tabular}
${ }^{* *} \mathrm{p}<.01$

Tablo 2'ye bakıldığı zaman regresyon analizinde kullanılacak helikopter anne tutumu ile yaşam doyumu $(\mathrm{r}=.-43 ; \mathrm{p}<.01)$ ile psikolojik iyi oluş $(\mathrm{r}=.-44$; $\mathrm{p}<.01)$ arasından negatif yönde anlamlı ilişkinin olduğu görülmüştür. Psikolojik iyi oluş ile yaşam doyumu $(\mathrm{r}=.75 ; \mathrm{p}<.01)$ arasından ise pozitif yönde anlamlı ilişki bulunmuştur. 
Üniversite Öğrencilerinin Annelerinden Algıladıklarn Helikopter Ebeveyn Tutumlarının Yaşam Doyumlarn ve Psikolojik İyi Oluşlan Üzerindeki Yordayıcı Rolüne İlişkin Bulgular

Değişkenler arasındaki ilişki incelendikten sonra basit doğrusal regresyon analizinin koşulları incelenmiştir. Regresyon analizinin yapılabilmesi için verilerin normal dağılıma sahip olması, doğrulsallık ve hata terimlerinin normal dağılım sergilemesi koşullarının sağlanması gerektirği ifade edilmektedir (Tabachnick ve Fidell, 2013). Tablo 1 incelendiğinde verilen normal dağılıma sahip olduğu görülmektedir. Diğer açıdan normallik varsayı$\mathrm{m}$ için histogram ve doğrusallık varsayımının değerlendirilmesine için p-p plot grafikleri incelemiş, Şekil-1 ve Şeki-2'de sunulmuştur.
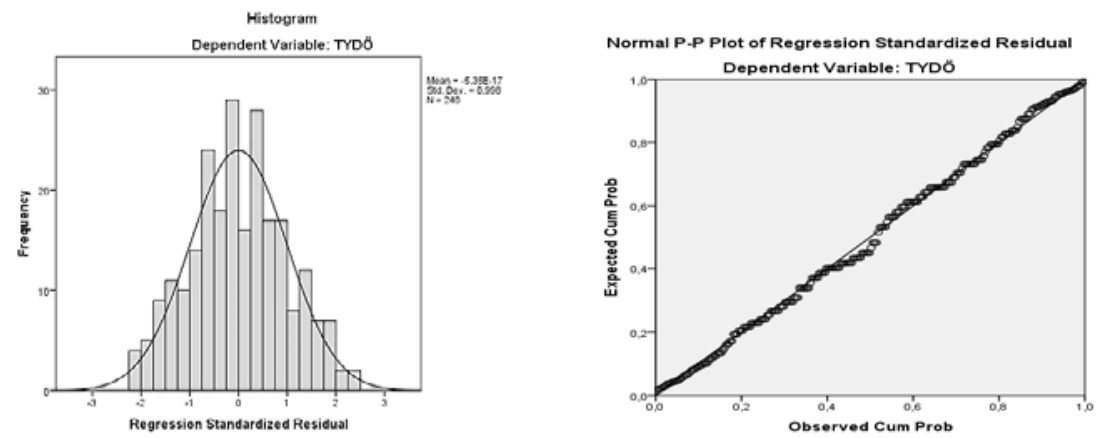

Şekil-1: Üniversite Öğrencilerinin Yaşam Doyumlarna İlişkin Puanların Histogram ve P-P Plot Grafiği
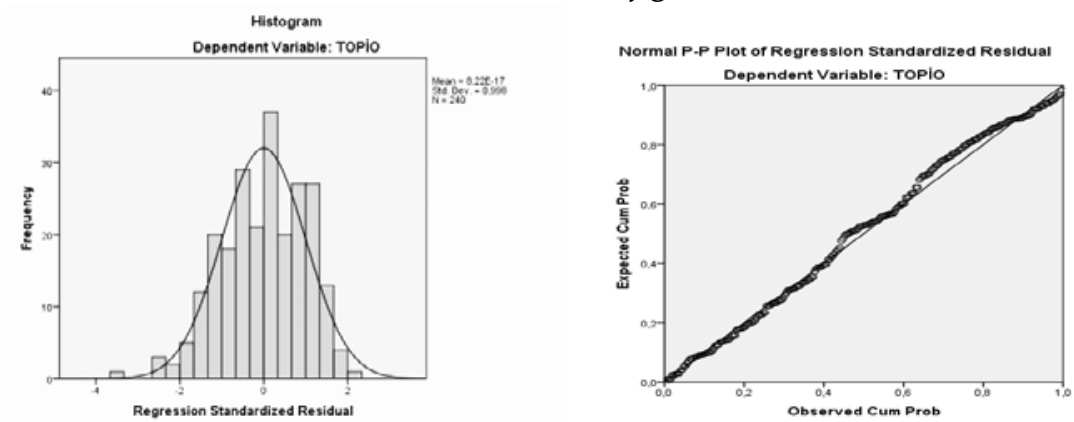

Şekil-2: Üniversite Öğrencilerinin Psikolojik İyi Oluş Puanlarna İlişkin Histogram ve P-P Plot Grafiği 
Şekil-1 ve Şekil-2 incelendiği zaman regresyon analizinin doğrusallık ve normallik koşullarının sağlandığı görülmektedir. Regresyon analizinin tüm koşulları sağlandıktan sonra üniversite öğrencilerinin annelerinden algıladıkları helikopter ebeveyn tutumlarının yaşam doyumları ve psikolojik iyi oluşları üzerindeki yordayıcı rolünü incelemek için basit doğrusal regresyon analizi yapılmış, analiz sonuçları sırasıyla Tablo 3 ve Tablo 4'de sunulmuştur.

Tablo 3. Anneden algılanan helikopter ebeveyn tutumlarinin yaşam doyumu üzerindeki yordayici rolï

\begin{tabular}{|c|c|c|c|c|c|c|c|c|}
\hline \multirow[t]{2}{*}{ Değişkenler } & B & \multirow[t]{2}{*}{ SH } & $\beta$ & \multirow[t]{2}{*}{$t$} & \multirow[t]{2}{*}{$\mathbf{p}$} & \multirow[t]{2}{*}{ Tolerans } & \multirow[t]{2}{*}{ VIF } & \multirow{2}{*}{$\begin{array}{l}\Delta \mathrm{R}^{2} \\
\text { (Düzeltişmiş) }\end{array}$} \\
\hline & $\begin{array}{l}\text { Standardize } \\
\text { Edilmemiş }\end{array}$ & & $\begin{array}{l}\text { Standardize } \\
\text { Edilmiş }\end{array}$ & & & & & \\
\hline Sabit & 22.87 & .93 & & $24.57^{*}$ & .000 & & & .18 \\
\hline $\begin{array}{l}\text { Helikopter } \\
\text { Anne Tutumu }\end{array}$ & -.14 & .019 & $-.43^{*}$ & $-.7 .34^{*}$ & & 1.000 & 1.000 & \\
\hline
\end{tabular}

*p <.001 (Regresyon eşitliği: Yaşam Doyumu = 22.87- 0.14xHelikopter Anne Tutumu)

Tablo 3'de görüldüğü üzere üniversite öğrencilerinin annelerinden alg1ladıkları helikopter ebeveyn tutumları yaşam doyulmalarını anlamlı olarak negatif yönde yordamışır [ $\left.\mathrm{F}_{238.1}=54.085 ; \mathrm{p}<.001\right]$. Yapılan analizin sonucuna göre helikopter anne tutumu değişkeninin Beta değeri -.43 olarak hesaplanmıştır. Bu sonuç üniversite öğrencilerinin annelerinden algıladıkları helikopter ebeveyn tutumları yükseldikçe yaşam doyumu düzeylerinde azalma olacağına işaret etmektedir. Ayrıca helikopter anne tutumu değişkeni yaşam doyumu değişkenine ait varyansın $\% 18^{\prime}$ ini açıklama gücü elde etmiştir.

Tablo 4. Anneden algılanan helikopter ebeveyn tutumlarinin psikolojik iyi oluş üzerindeki yordayici rolï

\begin{tabular}{|c|c|c|c|c|c|c|c|c|}
\hline \multirow[t]{2}{*}{ Değişkenler } & B & \multirow[t]{2}{*}{ SH } & $\beta$ & \multirow[t]{2}{*}{$t$} & \multirow[t]{2}{*}{ p } & \multirow[t]{2}{*}{ Tolerans } & \multirow[t]{2}{*}{ VIF } & \multirow{2}{*}{$\begin{array}{l}\Delta \mathrm{R}^{2} \\
\text { (Düzeltişmiş) }\end{array}$} \\
\hline & $\begin{array}{l}\text { Standardize } \\
\text { Edilmemiş }\end{array}$ & & $\begin{array}{l}\text { Standardize } \\
\text { Edilmiş }\end{array}$ & & & & & \\
\hline Sabit & 54.064 & 1.19 & & $27.85^{*}$ & .000 & & & .19 \\
\hline $\begin{array}{l}\text { Helikopter } \\
\text { Anne Tutumu }\end{array}$ & -.30 & .041 & $-.44^{*}$ & $-.7 .45^{*}$ & & 1.000 & 1.000 & \\
\hline
\end{tabular}

${ }^{*} \mathrm{p}<.001$ (Regresyon eşitliği: Psikolojik İyi Oluş = 54.064 - 0.30 x Helikopter Anne Tutumu)

Tablo 4 incelendiği zaman üniversite öğrencilerinin annelerinden algıladıkları helikopter ebeveyn tutumları psikolojik iyi oluş düzeylerinin anlamlı olarak negatif yönde yordadığı görülmektedir [ $\left.\mathrm{F}_{238.1}=55.468 ; \mathrm{p}<.001\right]$. Yap1lan analizde helikopter anne tutumu değişkeninin Beta değeri -.44 olarak 
hesaplanmıştır. Bu bulgu üniversite öğrencilerinin annelerinden algıladıkları helikopter ebeveyn tutumları yükseldikçe psikolojik iyi oluş düzeylerinde azalmanın oluşacağına işaret etmektedir. Ayrıca helikopter anne tutumu değişkeni yaşam doyumu değişkenine ait varyansın \%19'ini açıklama gücü elde etmiştir.

\section{Tartışma ve Sonuç}

Bu araştırmada üniversite öğrencilerinin annelerinden algıladıkları helikopter ebeveyn tutumlarının yaşam doyumları ve psikolojik iyi oluşları üzerindeki yordayıcı etkisi incelenmiştir.

Araştırmanın ilk bulgusuna göre üniversite öğrencilerinin annelerinden algıladıkları helikopter tutumlarının yaşam doyumları üzerinde negatif yönde anlamlı bir yordayıcı etkisinin olduğu görülmüştür. Araştırmada elde edilen bu sonucuna göre anneden algilanan helikopter ebeveyn tutumu yükseldikçe üniversite öğrencilerinin yaşam doyum düzeylerinde azalmanın meydana geleceği söylenebilir. Yeni bir araştırma konusu olan helikopter ebeveyn tutumları ile ilgili alanyazında sınırlı sayıda araştırma bulunmaktadır. Örneğin, Yılmaz ve Büyükcebeci (2019) yapmış oldukları araştırmalarında anneden algılanan helikopter ebeveyn tutumlarının ergenlerin yaşam doyumları üzerinde negatif bir yordayıcı rolünün olduğu sonucuna ulaşmışlardır. Benzer şekilde başka bir araştırmada helikopter ebeveyn tutumlarına maruz kalan üniversite öğrencilerinin yaşam doyumu düzeylerinin diğer bireylere gore anlamlı olarak daha düşük olduğu görülmüştür (Somers ve Stelle, 2010). Aynı şekilde başka bir araştırmada helikopter ebeveyn tutumlarına sahip anne-babası olan lise öğrencilerinin yaşam doyumlarının diğer lise öğrencilerine göre daha düşük olduğu görülmüştür (Schiffrin ve vd., 2013). Helikopter ebeveyn tutumu ile yaşam doyumu arasındaki ilişkiyi inceleyen diğer çalışmalarda benzer sonuçların rapor edildiği görülmektedir (Odenweller, Booth-Butterfield ve Weber, 2014; Segrin ve vd., 2012; Vinson, 2012). Sonuç olarak mevcut araştırma bulgusu ile alanyazındaki araştırma sonuçlarının benzer olduğu söylenebilir. Bilindiği üzere alanyazında çocukların bilişsel, duyuşsal, davranışsal ve sosyal açıdan sağlıklı bir gelişim göstermeleri ile ebeveyn tutumları arasında önemli bir ilişkinin olduğu vurgulanmaktadır (Vera, Granero ve Ezpeleta, 2012; Yörükoğlu, 2006). Kuramsal alanyazında anne-baba tutumlarının bireylerin kişilik, 
sosyal ve duygusal gelişimleri üzerinde önemli belirleyicilerden biri olduğu vurgulanmasına rağmen çocuk ile anne arasında kurulan ilişkinin ayrı bir öneme sahip olduğu vurgulanmaktadır (Huver, Otten, Vries ve Engels, 2010; Dağlı ve Beyazsaçlı, 2010; Jaureguizar, Bernaras, Bully ve Garaigordobil, 2018). Bu nedenle ailede anne-baba-çocuk ilişkisinde anne ile çocuk arasinda kurulan ilişkinin daha önemli olduğu söylenmektedir (Ericson, 1980; Oh ve Lee, 2010). Çünkü anne çocuğa ilk bakım veren kişi konumunda bulunmakta ve çocuğu ile temel güvene duygusuna bağlı kuracağı ilk ilişkinin bireyin sonraki yaşamı üzerinde etkili olacağı ifade edilmektedir (Ericson, 1980; Yörükoğlu, 2006). Bunun yanı sıra annenin çocuğuna yönelik tutum ve davranışlarının bireylerin sağlıklı bir gelişim geçirmelerinde temel bir unsur olarak kabul edilmektedir (Özensel, 2004; Won \& Hanna, 2018). Helikopter ebeveyn tutumu ise sürekli olarak çocuklarının etrafında olan ve onları korumaya çalışan, çocukları adına onların tüm sorumluluklarının yerine getirmeye çalışan bir ebeveynlik tarzı (Lee ve Kang, 2018) olduğu göz önüne alındığında çocukla daha fazla vakit geçiren ve helikopter ebeveyn tutumlarına sahip olan bir annenin, bu tutuma sahip babaya kıyasla çocuğun ruhsal dünyası üzerinde daha fazla etkisinin olabileceği değerlendirilebilir. Bu açıklamalara bakılarak mevcut araştırmada elde edilen bulgunun kuramsal alanyazınla da örtüştüğü ifade edilebilir.

Araştırmanın elde edilen diğer bir bulguya göre üniversite öğrencilerinin annelerinden algıladıkları helikopter ebeveyn tutumlarının psikolojik iyi oluş düzeyleri üzerinde anlamlı olarak negatif bir yordayıcı etkiye sahip olduğu belirlenmiştir. Bu sonuç üniversite öğrencilerin annelerinden algıladıkları helikopter ebeveyn tutumları yükseldikçe psikolojik iyi oluş düzeylerinde düşüş olacağı şeklinde yorumlanabilir. Alanyazında elde edilen bu bulguyu destekleyen bazı çalışmalar bulunmakyadır. Yapılan bir araştırmada üniversite öğrencilerinin annelerinden algıladıkları helikopter ebeveyn tutumlarının psikolojik iyi oluşları negatif yönde yordadığı sonucuna ulaşılmıştır (Yılmaz ve Büyükcebeci, 2019). Benzer şekilde üniversite öğrencileri üzerinde yapılan başka bir araştırmada aşırı baskıcı ve aşırı koruyucu ebeveynlere sahip öğrencilerin psikolojik iyi oluş düzeyinin düşük olduğu saptanmıştır (LeMoyne ve Buchanan 2011). Yapılan bir diğer çalışmada helikopter ebeveynler tutumlarına maruz kalan çocukların bağımlı kişilik özellikleri sergiledikleri ve psikolojik iyi oluş düzeylerinin düşük olduğu sonucuna ulaşılmıştır (Rousseau ve Scharf, 2017). Alanyazında bu konuda 
yapılan başka çalışmaların sonuçlarının da benzer olduğu görülmektedir (Erkan, 2019; Kouros, Pruitt, Ekas, Kiriaki ve Sunderland, 2017; LeMoyne ve Buchanan, 2011). Bu sonuçlara göre üniversite öğrencilerinin geçmişinde ya da şimdiki yaşamında annelerinden algıladıkları helikopter tutum düzeyleri yükseldikçe psikolojik iyi oluş düzeylerinde azalmanın meydana geleceğine işaret etmektedir.

Diğer açıdan araştırmada elde edilen bulgunun psikolojik iyi oluş ile helikopter ebeveynlik kavramlarının kuramsal yapısıyla da örtüştüğü görülmektedir. Psikolojik iyi oluş kendini kabul, olumlu sosyal ilişkiler sahip olma, özerk olma, çevresini kontrol edebilme kapasitesi bulunma, yaşamın anlamı ve kendini geliştirmesi motivasyonu gibi boyutlardan oluşmaktadır (Keyes, Shmotkin ve Ryff, 2002). Helikopter ebeveynlik ise çocuklarının üzerine aşırı bir şekilde düşen, çocukların tüm gelişim alanlarıyla ihtiyaç duyulandan fazla ilgilenen, çocukları adına karar veren, zorlukları ve problemleri çocukları adına çözmeye çalışan aşırı koruyucu anne baba tutumları olarak ifade edilmektedir (Cline ve Fay, 1990). Her iki tanım birlikte incelendiği zaman helikopter bir anneye sahip olan bireylerin psikolojik iyi oluşun bileşenleri olan özerk olma, çevresel kontrol becerisi kullanabilme ve kendini geliştirme motivasyonunu gibi faktörlerinin gelişmesine engel teşkil edecebileceği görülmektedir. Çünkü helikopter ebeveynler küçük yaşlardan itibaren çocuklarının kıyafet seçmeleri, arkadaşlık ilişkileri, okul ve meslek tercihlerine varana kadar birçok alanda çocuklarına müdahale etmekte ve onlar adına karar vermektedirler (Ganaprakasam, Davaidass ve Muniandy, 2018). Bu durum ilerleyen zamanlarda çocukları duygusal ve sosyal yönden olumsuz etkilenmesine neden olabilmektedir (Padilla-Walker, Nelson, 2012; Segrin ve vd., 2015). Tüm bu açıklamalara bakıldığı zaman mevcut araştırma sonucunun kuramsal alanyazın tarafından da desteklendiği ve helikopter anne tutumları ile üniversite öğrencilerinin psikolojik iyi oluşları arasındaki negatif ilişkinin beklenen bir sonuç olduğu söylenebilir. Sonuç olarak üniversite öğrencilerinin annelerinden algıladıkları helikopter ebeveynlik tutumlarının öğrencilerin yaşam doyumlarını ve psikolojik iyi oluşlarını olumsuz yönde etkilediği görülmüş̧ür. Bu araştırma sonucunda elde edilen bulgulara göre aşağıdaki öneriler geliştirilmiştir:

Çocukların fiziksel, ruhsal ve sosyal gelişimleri üzerinde etkili olan en önemli faktörlerden biri ebeveyn tutumlarıdır. Hatta bireylerin çocukluk döneminde karşılaştıkları olumlu veya olumsuz ebeveyn tutumları onların 
daha sonraki yaşamları üzerindeki etkili olabilmektedir. Son yıllarda helikopter ebeveynlik tarzlarının giderek arttığı görülmektedir. Bu nedenle anne-babalara, helikopter ebeveyn tutumlarının çocukların gelişimi üzerindeki etkisini içeren farkındalık eğitimleri verilebilir. Diğer açıdan Türkiye'de helikopter ebeveyn tutumları ile ilgili sınırlı sayıda araştırma bulunmakta ve mevcut araştırma sınırlı bir örneklem grubu üzerinde gerçekleştirilmiştir. $\mathrm{Bu}$ nedenle ileride yapılacak olan çalışmalarda daha geniş bir örneklem grubu ile çalışılarak, helikopter ebeveyn tutumunun bireylerin ruh sağlıkları üzerindeki etkisine ilişkin daha genelebilir sonuçların elde edileceği çalışmalar tasarlanabilir. Ayrıca ileride yapılacak başka bir artaştırmada helikopter ebeveynlere sahip bireylerin iş doyumları ile evlilik doyumlarının incelediği bir çalışma yapılabilir. 


\title{
EXTENDED ABSTRACT
}

\section{Helicopter Mother Attitudes: The Predictive Role in University Students' Life Satisfaction and Psychological Well-Being}

\author{
Faruk Caner Yam - Hatice Kumcağız \\ Tokat Gaziosmanpaşa University- Ondokuz Mayıs University
}

Helicopter parenting refers to overprotective, over controlling and intrusive parent attitudes (Cline and Fay, 1990). Helicopter parents are overly focused on their children's development and constantly try to shield their children by solving challenges and problems and taking decisions on behalf of their children (Reed, Duncan, Lucier-Greer and Fixelle, 2016). Although helicopter parents seem to care about their children's well-being, their approach has many negative effects on children (Gibbs, 2009). Previous studies have reported poor problem-solving skills, lack of self-confidence, and low psychological endurance in children with helicopter parents (Pdilla-Walker and Nelson, 2012; Rutherford, 2011).

Previous studies have also suggested that helicopter parenting also causes low academic achievement, perfectionist and narcissistic personality development, and failure to form their own identity (LeMoyne \& Buchanan, 2011; Odenweller, Booth-Butterfield and Weber, 2014; Tyler, 2007). Results from earlier studies have also demonstrated that children raised by helicopter parents face problems in career selection and have high interpersonal dependence and low life satisfaction (Odenweller et al., 2014; Schiffrin et al., 2013). Although the existing literature suggest that helicopter parent attitudes may have a negative effect on all developmental domains and periods of individuals, there is little published research on adults. For all these reasons, this study aimed to examine the predictive role of university students' perceived helicopter mother attitudes in their life satisfaction and psychological well-being. For this purpose, it has been tried to find answers to the following questions:

1- Do university students' perceived helicopter mother attitudes have a significant predictor effect on their life satisfaction? 
2- Do university students' perceived helicopter mother attitudes have a significant predictor effect on their psychological well-being?

In this study, the relational scanning model was used. Study group of the research consisted of 240 university students (166 females and 74 males) selected using convenience sampling method. The data were collected using the Helicopter Parenting Scale, Satisfaction with Life Scale, and Psychological Well-being Scale. The data were first analysed using descriptive statistics. The Pearson product-moment correlation coefficient was used to analyse the correlation between psychological well-being, life satisfaction and perceived helicopter mother attitudes. Simple linear regression was used to analyse the predictive role of perceived helicopter mother attitudes in university students' life satisfaction and psychological well-being.

The analysis results showed that university students' perceived helicopter mother attitudes have a negative predictor effect on their life satisfaction and psychological well-being. Accordingly, university students' life satisfaction decreased with the increase in perceived helicopter mother attitudes. Likewise, university students' psychological well-being decreased with the increase in perceived helicopter mother attitudes. In parallel with the present study, a previous studies also found that university students' perceived helicopter mother attitudes are a negative predictor of their psychological well-being (Somer and Stelle, 2010; Yllmaz and Büyükcebeci, 2019; Weber, 2014).

The definitions of psychological well-being and helicopter parenting also theoretically support the results of this study. Psychological well-being consists of components such as self-acceptance, positive social relationships, autonomy, control over the environment, the meaning of life, and selfimprovement motivation (Keyes, Shmotkin and Ryff, 2002). Considering the above-mentioned description of helicopter parenting, the development of the components of psychological well-being, i.e. autonomy, control over the environment, and self-improvement motivation, is hindered in individuals who have a helicopter mother. Helicopter parents are overly involved in their children's lives and decide on behalf of their children starting from an early age. For example, they decide what their children wear and intervene in their friendship relations and school and career choices. This may cause negative emotional and social effects on children in later years. In light of these explanations, the results of this study are consistent with the theoretical literature and it is an expected result that there is a negative correlation 
between university students' perceived helicopter mother attitudes and psychological well-being.

It can be stated that the present research finding is predictable in terms of developmental theories. In the literature, it is emphasized that there is an important relationship between parents' attitudes and their healthy development, not having problematic behaviors and their social development (Yörükoğlu, 2006). Although it is stated that parental attitudes are one of the important determining factors on the personality, social and emotional development of individuals, it is stated that the relationship the child establishes with the mother has a special importance(Huver, Otten, Vries, and Engels, 2010; Mountain and Whitehair, 2010; Jaureguizar, Bernaras, Bully, and Garaigordobil, 2018). Because the mother is in the position of the first caregiver to the child and it is stated that the first relationship with the child based on the basic sense of trust affects the individual's later life (Ericson, 1980; Yörükoğlu, 2006). Helicopter parental attitude is a parenting style that is constantly around and tries to protect their children, and tries to fulfill all their responsibilities on behalf of their children. Considering this situation, it can be thought that a mother who spends more time with the child and who has helicopter parental attitudes can have more impact on the psychological development of the child compared to the father with this attitude.

All in all, the study found that university students' perceived helicopter mother attitudes negatively affect their life satisfaction and psychological well-being. Therefore, in another study to be conducted in the future, the predictive effect of helicopter father attitudes on life satisfaction and psychological well-being of university students can be investigated. On the other hand, a descriptive study can be conducted to examine job satisfaction, marital satisfaction and social anxiety of individuals with helicopter parents. In addition, awareness trainings on helicopter parenting can be given to families.

\section{Kaynakça / References}

Appleton, S. ve Song, L. (2008). Life satisfaction in urban China: Components and determinants. World Development, 36(11), 2325-2340.

Bradley-Geist, J. C. ve Olson-Buchanan, J. B. (2014). Helicopter parents: An examination of the correlates of over-parenting of college students. Education+ Training. 56(4), 314-328. 
Büyüköztürk, Ş., Çakmak, E. K., Akgün, Ö. E., Karadeniz, Ş. ve Demirel, F. (2017). Bilimsel araştırma yöntemleri. Ankara: Pegem Akademi Yayınları.

Cline, F. W. ve Fay, J. (1990). Parenting with love and logic: Teaching children responsibility. Colorado Springs, CO: Pinon.

Dağlı, G. ve Beyazsaçlı, M. (2010). Ana-baba tutumu ve kendini gerçekleştirme düzeyleri arasındaki ilişkinin değerlendirilmesi. Mediterranean Journal of Educational Research, 7, 1-16.

Diener, E., Scollon, C. N. ve Lucas, R. E. (2009). The evolving concept of subjective well-being: The multifaceted nature of happiness. In Assessing well-being (s. 67-100). Springer, Dordrecht.

Diener, E. (1984). Subjective well-being. Psychological Buletin, 95 (3), 542-575.

Diener, E. (2000). Subjective well-being: The science of happiness and a proposal for a national index. American Psychologist, 55 (1), 34-43.

Diener, E., Emmons, R. A., Larsen, R. J. ve Griffin, S. (1985). The satisfaction with life scale. Journal of Personality Assessment, 49(1), 71-75.

Erikson, E. H. (1980). Elements of a psychoanalytic theory of psychosocial development. Psychoanalytic contributions toward understanding personality development. The Course of Life,1, 11-61.

Ganaprakasam, C., Davaidass, K.S. ve Muniandy, S.C. (2018). Helicopter parenting and psychological consequences among adolescent. International Journal of Scientific and Research Publications, 8(6), 378-382.

Gibbs, N. (2009). The growing backlash against overparenting. 20.08.2020 tarihinde http://content.time.com/time/subscriber/article/0,33009,1940697-7,00.html adresinden erişim sağlanmıştır.

Han, J. W., Lee, H. (2018). Effects of parenting stress and controlling parenting attitudes on problem behaviors of preschool children: latent growth model analysis. Journal of Korean Academy of Nursing, 48(1), 109-121.

Huver, R. M. E., Otten, R., Vries, H. D. ve Engels, C. M. E. (2010). Personality and parenting style in parents of adolescents. Journal of Adolescence, 33, 395-402

Jaureguizar, J., Bernaras, E., Bully, P. ve Garaigordobil, M. (2018). Perceived parenting and adolescents' adjustment. Psicologia: Reflexão e Crítica,31(8),1-11.

Keyes, C. L., Shmotkin, D. ve Ryff, C. D. (2002). Optimizing well-being: the empirical encounter of two traditions. Journal of Personality and Social Psychology, 82(6), 1007-1022. 
Kins, E., Beyers, W., Soenens, B. ve Vansteenkiste, M. (2009). Patterns of home leaving and subjective well-being in emerging adulthood: The role of motivational processes and parental autonomy support. Developmental Psychology, 45, 1416-1429.

Kouros, C. D., Pruitt, M. M., Ekas, N. V., Kiriaki, R. ve Sunderland, M. (2017). Helicopter parenting, autonomy support, and college students' mental health and well-being: The moderating role of sex and ethnicity. Journal of Child and Family Studies, 26(3), 939-949.

Köker, S. (1991). Normal ve sorunlu ergenlerin yaşam doyumu düzeylerinin karşlaştırlması. Yayınlanmamış yüksek lisans tezi. Ankara Üniversitesi Sosyal Bilimler Enstitüsü, Ankara.

Le Moyne, T. ve Buchanan, T. (2011). Does "hovering" matter? Helicopter parenting and its effect on well-being. Sociological Spectrum, 31(4), 399-418.

Lee. J. ve Kang, S. (2018). Perceived helicopter parenting and Korean emerging adults' psychological adjustment: The mediational role of parent-child affection and pressure from parental career expectations. Journal of Child and Family Studies, 27(11), 3672-3686.

Luyckx, K., Vansteenkiste, M., Goossens, L. ve Duriez, B. (2009). Basic need satisfaction and identity formation: Bridging self-determination theory and processoriented identity research. Journal of Counseling Psychology, 56, 276-288.

Lyubomirsky, S., Sousa, L. ve Dickerhoof, R. (2006). The costs and benefits of writing, talking, and thinking about life's triumphs and defeats. Journal of Personality and Social Psychology, 90(4), 692.

Myers, D. G., ve Diener, E. (1995). Who is happy?. Psychological science, 6(1), 10-19.

Nelson, M. (2010). Why do we worry about helicopter parents. Psychology Today, 20.08.2020 tarihinde http://www.https://www.psychologytoday.com/us/blog/anxious-parentsin-uncertain times/201006/why-do-we-worry-about-helicopter-parents adresinden erişildi.

Odenweller, K. G., Booth-Butterfield, M. ve Weber, K. (2014). Investigating helicopter parenting, family environments, and relational outcomes for millennials. Communication Studies, 65(4), 407-425.

Oh YK, Lee HS. (2010). The effects of individual psychology, family environment and social environment factors on adolescents' behavior problems. Korean Journal of Home Economics Education. 22(1),51-64

Özensel, E. (2004). Türk toplumunda çocuğun yetiştirilmesinde annenin rolü: Konya İli örneği. Değerler Eğitimi Dergisi, 2(6), 77-96. 
Padilla-Walker, L. M. ve Nelson, L. J. (2012). Black hawk down?:Establishing helicopter parenting as a distinct construct fromother forms of parental control during emerging adulthood. Journal of Adolescence, 35, 1177-1190.

Rousseau, S. ve Scharf, M. (2017). Why people helicopter parent? An actor-partner interdependence study of maternal and paternal prevention/promotion focus and interpersonal/self-regret. Journal of Social and Personal Relationships, 35(7), 919-935.

Reed, K., Duncan, J. M., Lucier-Greer, M., Fixelle, C. ve Ferraro, A. J. (2016). Helicopter parenting and emerging adult self-efficacy: Implications for mental and physical health. Journal of Child and family Studies, 25(10), 3136-3149.

Rutherford, M. B. (2011). The social value of self-esteem. Social Science and Public Policy, 48, 407-412.

Ryff, C. D. (1989). Happiness is everything, or is it? Explorations on the meaning of psychological well-being. Journal of Personality And Social Psychology, 57(6), 1069.

Ryff, C. D. (2014). Psychological well-being revisited: Advances in the science and practice of eudaimonia. Psychotherapy and Psychosomatics, 83, 10-28.

Ryff, C. D. (2018). Well-Being with soul: Science in pursuit of human potential. Perspectives on Psychological Science, 13(2), 242-248.

Seligman, M. E. (2011). Flourish: a visionary new understanding of happiness and well-being. Policy, 27(3), 60-61.

Segrin, C., Woszidlo, A., Givertz, M., Dauer, A. ve Murphy, M. T. (2012). The association between overparenting, parent-child communication, and entitlement and adaptive traits in adult children. Family Relations, 61, 237-252.

Segrin, C., Givertz, M., Swaitkowski, P. ve Montgomery, N. (2015).Overparenting is associated with child problems and a criticalfamily environment. Journal of Child and Family Studies, 24(2),470-479.

Schiffrin, H. H., Liss, M., Miles-McLean, H., Geary, K. A., Erchull, M. J., ve Tashner, T. (2014). Helping or hovering? The effects of helicopter parenting on college students' well-being. Journal of Child and Family Studies, 23(3), 548-557.

Shoup, R., Gonyea, R. M. ve Kuh, G. D. (2009). Helicopter parents: Examining the impact of highly involved parents on student engagement and educational outcomes. In 49th Annual Forum of the Association for Institutional Research, Atlanta,

Georgia. 20.08.2020tarihindehttp://cpr.indiana.edu/uploads/AIR\%202009\%20Impact \%20of\%20Helicopter\%20Parents.pdf adresinden erişim sağlanmıştır. 
Somers, P. ve Settle, J. (2010). The helicopter parent: Research toward a typology. College and University: The Journal of the American Association of Collegiate Registrars, 86(1), 18-27.

Suldo, S. M., Riley, K. N. ve Shaffer, E. J. (2006). Academic correlates of children and adolescents' life satisfaction. School Psychology International, 27(5), 567-582.

Tabachnick, B. G. ve Fidell, L. S. (2013). Using multivariate statistics. (Sixth edition). Boston: Pearson

Tyler, K. (2007). The tethered generation. HR Magazine, 52(5), 41-46. 20.08.2020 tarihindehttp://www.shrm.org/Publications/hrmagazine/EditorialContent/ Pages/0507cover.aspx. adresinden erişim sağlanmıştır.

Telef, B. B. (2013). Psikolojik iyi oluş ölçeği: Türkçeye uyarlama, geçerlik ve güvenirlik çalışması. Hacett epe Üniversitesi Eğitim Fakültesi Dergisi, 28(3), 374-384.

Vera, J., Granero, R. ve Ezpeleta L. (2012). Father's and mother's perceptions of parenting styles as mediators of the effects of parental psychopathology on antisocial behavior in outpatient children and adolescents. Child Psychiatry \& Human Development. 43(3), 376- 392.

Vinson, K. (2012). Hovering too close: The ramifications of helicopter parenting in higher education. Georgia State University Law Review., 29(2), 423-452.

Yılmaz, H., Büyükcebeci,A. (2019). Bazı pozitif psikoloji kavramları açısından helikopter ebeveyn tutumlarının sonuçları. Türk Psikolojik Danışma ve Rehberlik Dergisi 9(54), 707-744.

Yılmaz, H. (2019). İyi ebeveyn, çocuğu için her zaman her şeyi yapan ebeveyn değildir: Algilanan Helikopter Ebeveyn Tutum Ölçeği (AHETÖ) geliştirme çalışması. Erken Çocukluk Çalışmalan Dergisi, 3(1), 3-31.

Yörükoğlu, A. (2006). Çocuk ruh sağ lı̆̆g. (26. Baskı). İstanbul: Özgür Yayınları.

\section{Kaynakça Bilgisi / Citation Information}

Yam, C. F. ve Kumcağız, H. (2021). Helikopter anne tutumları: Üniversite öğrencilerinin yaşam doyumları ve psikolojik iyi oluşları üzerindeki yordayıcı rolü. OPUS-Uluslararası Toplum Araştırmaları Dergisi, 17(35), 1946-1967. DOI: 10.26466/opus.784171 